\title{
Yttrium Doping Effect on Varistor Properties of Zinc-Vanadium-Based Ceramics
}

\author{
Choon-W. Nahm ${ }^{\dagger}$ \\ Semiconductor Ceramics Laboratory, Department of Electrical Engineering, Dongeui University, Busan 47340, Korea
}

(Received June 28, 2018; Revised August 22, 2018; Accepted August 23, 2018)

\begin{abstract}
The influence of yttrium doping on varistor properties of zinc-vanadium-based ceramics was comprehensively investigated. The average grain size varied slightly between 5.2 and $5.5 \mu \mathrm{m}$ as the yttrium content increased; and similarly, the sintered density varied slightly between 5.47 and $5.51 \mathrm{~g} / \mathrm{cm}^{3}$. The threshold field exhibited a maximum value $(5387 \mathrm{~V} / \mathrm{cm})$ when the yttrium content was $0.1 \mathrm{~mol} \%$. The highest nonlinear exponent (67) was obtained when the yttrium content was 0.05 mol\%. The donor concentration increased in the range of $(2.46-5.56) \times 10^{17} \mathrm{~cm}^{-3}$ as the yttrium content increased, and the maximum barrier height was obtained $(1.24 \mathrm{eV})$ when the yttrium content reached $0.05 \mathrm{~mol} \%$.
\end{abstract}

Key words : Yttrium, Dielectric properties, Electrical properties, Zinc-vanadium-based ceramics

\section{Introduction}

A varistor is a voltage-dependent resistor or nonlinear resistor. Unlike a general resistor, its resistance changes according to the applied voltage. Materials exhibiting a varistor effect must have a microstructure such as a pn junction or an active grain boundary or an active interface. Zinc oxide varistors are made by adding several specified additives to zinc oxide and firing it at a proper temperature. ${ }^{1,2)}$ The microstructure of doped zinc oxide varistors is a polycrystalline composed of numerous semiconducting zinc oxide grains and grain boundaries. The grains are semiconductors with a band gap of $\sim 3.2 \mathrm{eV}$, and the grain boundaries are active for electrons and have a very thin insulating layer. As a result, one semiconductorinsulating layer-semiconductor (SIS) structure yields a microvaristor. Microvaristors are randomly distributed throughout a sintered body. Consequently, sintering zinc oxide doped with specified minor additives produces a distinctive microstructure and nonlinear conduction properties. Owing to the superior nonlinearity of zinc oxide varistors, they can be effectively applied to bypass various passive and active devices, protect electrical and electronic equipment from dangerous transient voltages, and protect electric facilities from lightning., ${ }^{1,3)}$

Today, most varistors are doped mainly with bismuth and partially with praseodymium. ${ }^{4,5}$ Because these varistor ceramics should be fired at a temperature higher than $1000^{\circ} \mathrm{C}$, expensive $\mathrm{Pd}$ or $\mathrm{Pt}$ is inevitably used for multilayering. ${ }^{6)}$ Moreover, Ag, with its excellent conductivity, can be

\footnotetext{
Corresponding author: Choon-W. Nahm

E-mail : cwnahm@deu.ac.kr

Tel : +82-51-890-1669 Fax : +82-505-182-6900
}

used as an inner electrode. Therefore, at this time, varistor ceramics that can be co-fired at a temperature lower than the melting point $\left(960^{\circ} \mathrm{C}\right)$ of $\mathrm{Ag}$ are required, making vanadium-doped zinc oxide ceramics suitable here. ${ }^{7,8)}$

Since $1994,{ }^{7}$ vanadium-doped zinc oxide varistors have been continuously studied. ${ }^{9-16)}$ Despite considerable improvements, however, they are still inadequate for practical use. ${ }^{14,17-19)}$ Nahm first reported that zinc-vanadium varistors doped with manganese-niobium oxides exhibited highly nonlinear properties. ${ }^{20)}$ On the basis of this composition, it was found that gadolinium additives significantly improved the nonlinearity of zinc-vanadium-based varistor ceramics. ${ }^{21)}$ Obtaining better varistor characteristics requires ongoing study.

In this work, we investigate the influence of yttrium dopants on the microstructure and electrical and dielectric characteristics of yttrium-doped zinc-vanadium-based ceramics and report a considerably high nonlinear exponent ( $\alpha=67$ ) for varistor ceramics.

\section{Experimental Procedure}

\subsection{Specimen preparation}

The composition formula for the specimens is as follows: $(97.4-x) \mathrm{ZnO}+0.5 \mathrm{~V}_{2} \mathrm{O}_{5}+2.0 \mathrm{MnO}_{2}+0.1 \mathrm{Nb}_{2} \mathrm{O}_{5}+x \mathrm{Y}_{2} \mathrm{O}_{3}$ (where $x=0.0,0.05,0.1$, and 0.25) (all in mol\%). The specimens were prepared in the following order using the traditional ceramic technique: The raw material was balanced with the composition expression and then ball milled for 24 $\mathrm{h}$ together with acetone as a dispersion medium. The mixture was dried at $120^{\circ} \mathrm{C}$ and granulated with a polyvinyl butyral (PVB) binder to use as a starting powder. The granulated powder was pressed into $1.5 \mathrm{~mm}$ thick disks of 10 $\mathrm{mm}$ diameter, under a pressure of $1000 \mathrm{~kg} / \mathrm{cm}^{2}$. The disks 
were set onto a magnesia plate and fired at $900^{\circ} \mathrm{C}$ for $3 \mathrm{~h}$. Lapping and polishing produced final disks of $8 \mathrm{~mm}$ diameter and $1.0 \mathrm{~mm}$ thickness. The surfaces of the disks were painted with a conductive silver paste, to use as electrodes, and then fired at $550^{\circ} \mathrm{C}$ for $10 \mathrm{~min}$.

\subsection{Microstructure analysis}

The fracture microstructure images of the sintered disks were examined under a field emission scanning electron microscope (Quanta 200). The average grain size $d$ was calculated using the expression $d=1.56 \mathrm{~L} / \mathrm{MN}$ proposed by Wurst et $a l .{ }^{22)}$ The phases of the sintered specimens were identified by X-ray diffraction (XRD) patterns using $\mathrm{CuK} \alpha$ radiation (X'pert-PRO MPD). The sintered densities $r$ were measured by using a density determination kit (238490) attached to a balance (AG 245).

\subsection{J-E characteristics measurement}

The current-voltage $(I-V)$ characteristics were automatically measured using a high-voltage source-measure unit (Keithley 237). The $I-V$ characteristics are converted to current density-electric field $(J-E)$ characteristics. The threshold voltage $V_{1 \mathrm{~mA} / \mathrm{cm}^{2}}$ was measured at $1.0 \mathrm{~mA} / \mathrm{cm}^{2}$. The leakage current $I_{\mathrm{L}}$ was measured at $0.8 V_{1 \mathrm{~mA} / \mathrm{cm}^{2}}$. The threshold field $E_{1 \mathrm{~mA} / \mathrm{cm}^{2}}$, the nonlinear exponent $\alpha$, and the leakage current density $J_{\mathrm{L}}$ are calculated from $E_{1 \mathrm{~mA} / \mathrm{cm}^{2}}=V_{1 \mathrm{~mA} / \mathrm{cm}^{2}} / D$, $\alpha=1 / \log \left(V_{10 \mathrm{~mA} / \mathrm{cm}^{2}} / V_{1 \mathrm{~mA} / \mathrm{cm}^{2}}\right)$, and $J_{\mathrm{L}}=I_{\mathrm{L}} / S$, respectively, where $D$ is the thickness of the specimens $(1 \mathrm{~mm})$ and $S$ is the area of the electrodes.

The capacitance-voltage $(C-V)$ characteristics were measured at a frequency of $1 \mathrm{kHz}$ and a bias voltage in the 0 $100 \mathrm{~V}$ range by using a precision LCR meter (QuadTech 7600) and an electrometer (Keithley 617) in a DC source. The donor concentration $N_{\mathrm{d}}$ and the barrier height $\Phi_{\mathrm{b}}$ were determined from the expression $\left(1 / C_{\mathrm{b}}-1 / 2 C_{\mathrm{bo}}\right)^{2}=2\left(\Phi_{\mathrm{b}}+V_{\mathrm{gb}}\right) /$ $q \varepsilon N_{\mathrm{d}}$ proposed by Mukae et al. $^{23)}$ The interface state density $N_{\mathrm{t}}$ between the grain and the intergranular layer in the grain boundary was calculated from the expression ${ }^{23)} N_{\mathrm{t}}=$ $\left(2 \varepsilon N_{\mathrm{d}} \Phi_{\mathrm{b}} / q\right)^{1 / 2}$.

\subsection{Dielectric characteristics measurement}

The apparent capacitance $C_{\mathrm{APP}}$ ' and dissipation factor tan $\delta$ were measured from $10 \mathrm{~Hz}$ to $1 \mathrm{MHz}$ by using an RLC meter (QuadTech 7600). The dielectric constant $\varepsilon_{\mathrm{APP}}$ ' was calculated from $C_{\mathrm{APP}}{ }^{\prime}=\varepsilon_{\mathrm{APP}}{ }^{\prime} S / D$.

\section{Results and Discussion}

Figure 1 presents the surface microstructures of $\mathrm{ZnO}$ ceramics doped with several yttrium contents. Seemingly, there is no detectable difference on the surface between the yttrium-free $\mathrm{ZnO}$ ceramics and the yttrium-doped $\mathrm{ZnO}$ ceramics. On the whole, the phase distribution is homogeneous. The average grain size $d$ according to the yttrium content is presented in Fig. 2. As the yttrium content increased, the average grain size $d$ decreased slightly from
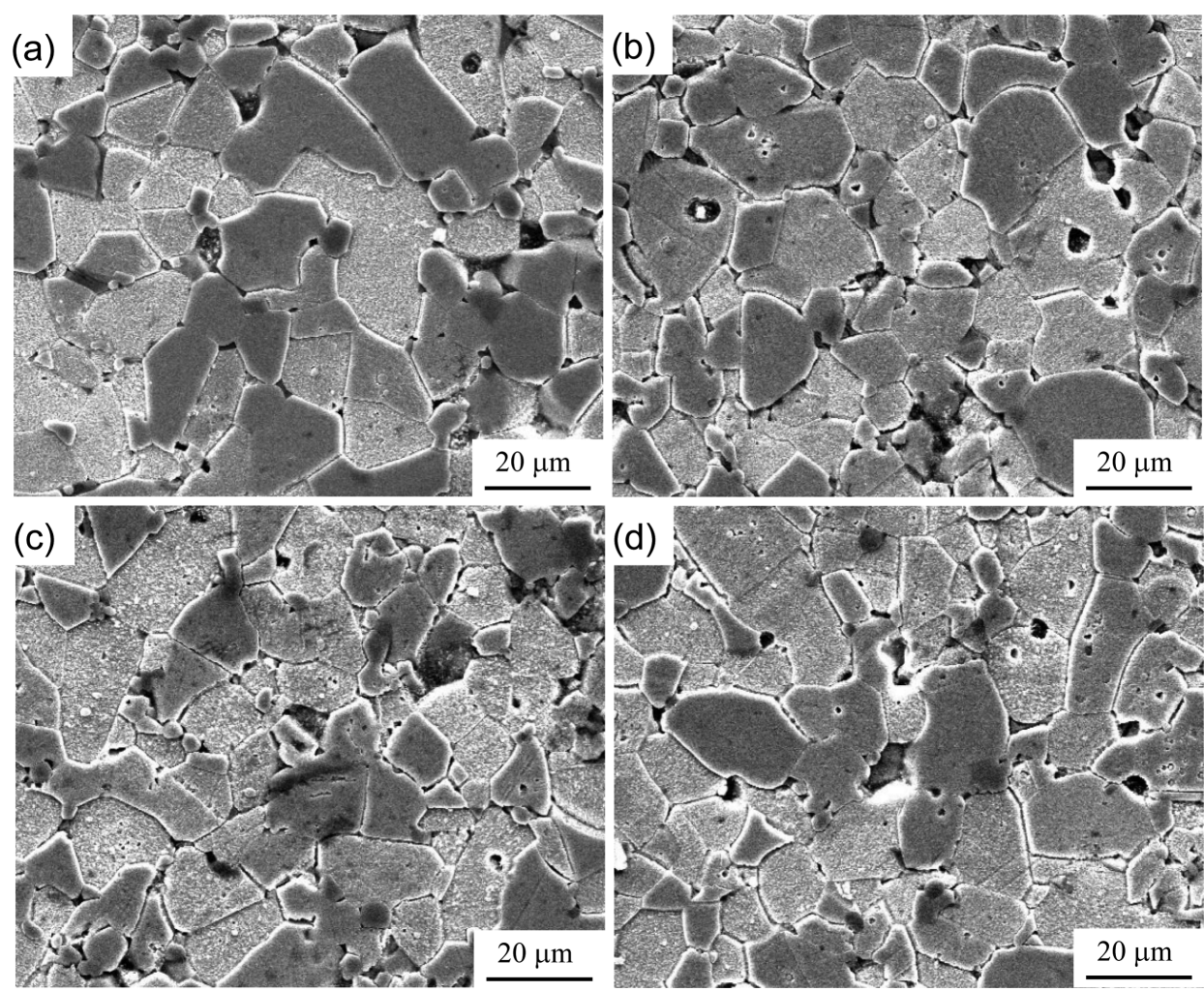

Fig. 1. Scanning electron microscope micrographs of $\mathrm{ZnO}$ ceramics doped with yttrium contents of (a) $0.0 \mathrm{~mol} \%$, (b) $0.05 \mathrm{~mol} \%$, (c) $0.1 \mathrm{~mol} \%$, and (d) $0.25 \mathrm{~mol} \%$. 


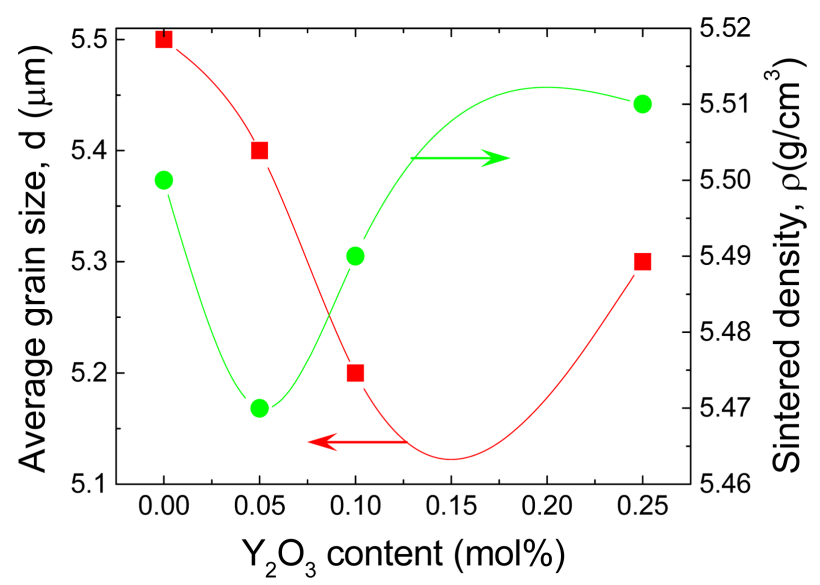

Fig. 2. Average grain size and sintered density of $\mathrm{ZnO}$ ceramics as a function of yttrium content.

5.5 to $5.2 \mu \mathrm{m}$ until the yttrium content reached $0.1 \mathrm{~mol} \%$. When the yttrium content exceeded $0.1 \mathrm{~mol} \%$, the average grain size $d$ increased to $5.3 \mu \mathrm{m}$. However, the change of the average grain size $d$ according to the yttrium content is not very great. The decrease in the average grain size $d$ is ascribed to the increase of $\mathrm{YVO}_{4}$ generated by doping with yttrium (see Fig. 3). The sintered density $\rho$ according to the yttrium content is presented in Fig. 2. The sintered density $\rho$ decreased slightly up to $0.05 \mathrm{~mol} \%$, whereas a further increase in the yttrium content increased the sintered density $\rho$ in the range of $5.47-5.51 \mathrm{~g} / \mathrm{cm}^{3}$. As the yttrium content increased, the change of the sintered density $\rho$, like the average grain size $d$, is not great. On the whole, the influence of yttrium doping on the microstructure is minor, when compared with other..$^{21)}$ A few microstructure parameters for several yttrium contents are summarized in Table 1.

Figure 3 presents the typical XRD patterns of $\mathrm{ZnO}$ ceramics doped with several yttrium contents. All the specimens revealed minor phases such as $\mathrm{VO}_{2}, \mathrm{ZnV}_{2} \mathrm{O}_{4}$, and $\mathrm{Zn}_{3}\left(\mathrm{VO}_{4}\right)_{2}$. The specimens doped with yttrium generated $\mathrm{YVO}_{4}$ as a minor phase.

Figure 4 presents the $J-E$ characteristics of $\mathrm{ZnO}$ ceramics doped with several yttrium contents. The $J-E$ characteristics comprise a high-impedance region below the knee voltage and a low-impedance region above the knee voltage. The distribution of $J-E$ curves shows that yttrium doping greatly affects the nonlinearity. With increasing yttrium content, the threshold field $E_{1 \mathrm{~mA} / \mathrm{cm}^{2}}$ increased in the range of 4874-5387 V/cm when the yttrium content reached 0.1

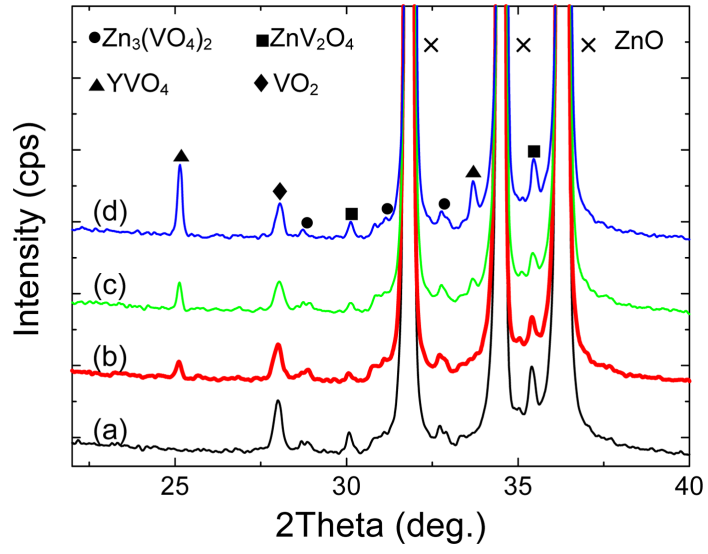

Fig. 3. XRD patterns of $\mathrm{ZnO}$ ceramics doped with yttrium contents of (a) $0.0 \mathrm{~mol} \%$, (b) $0.05 \mathrm{~mol} \%$, (c) $0.1 \mathrm{~mol} \%$, and (d) $0.25 \mathrm{~mol} \%$.

mol\%. When the yttrium content exceeded $0.1 \mathrm{~mol} \%$, the threshold field $E_{1 \mathrm{~mA} / \mathrm{cm}^{2}}$ decreased up to $5355 \mathrm{~V} / \mathrm{cm}$ at 0.25 mol\% yttrium. The behavior of the threshold field $E_{1 \mathrm{~mA} / \mathrm{cm}^{2}}$ with increasing yttrium content depends on the average grain size $d$. The decrease in the average grain size brings about an increase of the number of grain boundaries. All the specimens exhibited $v_{\mathrm{gb}}=2.7-2.8 \mathrm{~V} /$ (grain boundary) for the threshold voltage per grain boundaries regardless of the yttrium content.

The nonlinear exponent $\alpha$ according to the yttrium content is presented in Fig. 5. The $J-E$ curves in varistor ceramics all feature a nonlinear exponent $\alpha$. As the yttrium content increased, the nonlinear exponent $\alpha$ increased pronouncedly from 51 to 67 , until the yttrium content reached $0.05 \mathrm{~mol} \%$. When the yttrium content exceeded $0.05 \mathrm{~mol} \%$, the nonlinear exponent $\alpha$ decreased up to 40 at $0.25 \mathrm{~mol} \%$ yttrium. The specimen doped with $0.05 \mathrm{~mol} \%$ yttrium exhibited the largest $\alpha(\alpha=67)$ of the $\mathrm{ZnO}-\mathrm{V}_{2} \mathrm{O}_{5}$ systems known so far. ${ }^{21)}$ The abrupt decrease of the nonlinear exponent $\alpha$ at $0.25 \mathrm{~mol} \%$ in the yttrium content is ascribed to the decrease in the potential barrier height at the grain boundaries. Basically, the potential barrier is affected by various defects (interstitial zinc, interstitial oxygen, zinc vacancies, etc.) at the grain boundary. ${ }^{24,25)}$ Therefore, the nonlinear exponent $\alpha$ is strongly affected by the Schottky barrier. However, the behavior of the nonlinear exponent a according to the yttrium content may be connected with the content of $\mathrm{YbVO}_{4}$. That is, $\mathrm{YVO}_{4}$-free or excess $\mathrm{YVO}_{4}$ can reduce the nonlinear exponent $\alpha$. The leakage current density $J_{\mathrm{L}}$

Table 1. Microstructure and Electrical Characteristic Parameters of ZnO Ceramics Doped with Several Yttrium Contents

\begin{tabular}{ccccccc}
\hline $\begin{array}{c}\text { Yttrium content } \\
(\mathrm{mol} \%)\end{array}$ & $\begin{array}{c}\mathrm{d} \\
(\mu \mathrm{m})\end{array}$ & $\begin{array}{c}\rho \\
\left(\mathrm{g} / \mathrm{cm}^{3}\right)\end{array}$ & $\begin{array}{c}E_{1 \mathrm{~mA} / \mathrm{cm}^{2}} \\
(\mathrm{~V} / \mathrm{cm})\end{array}$ & $\begin{array}{c}v_{\mathrm{gb}} \\
(\text { V/grain boundary })\end{array}$ & $\begin{array}{c}J_{\mathrm{L}} \\
\left(\mu \mathrm{A} / \mathrm{cm}^{2}\right)\end{array}$ \\
\hline 0.0 & 5.5 & 5.50 & 4874 & 2.7 & 51 & 56.8 \\
0.05 & 5.4 & 5.47 & 4989 & 2.7 & 67 & 99.7 \\
0.1 & 5.2 & 5.49 & 5387 & 2.8 & 53 & 105.5 \\
0.25 & 5.3 & 5.51 & 5355 & 2.8 & 40 & 251.6 \\
\hline
\end{tabular}



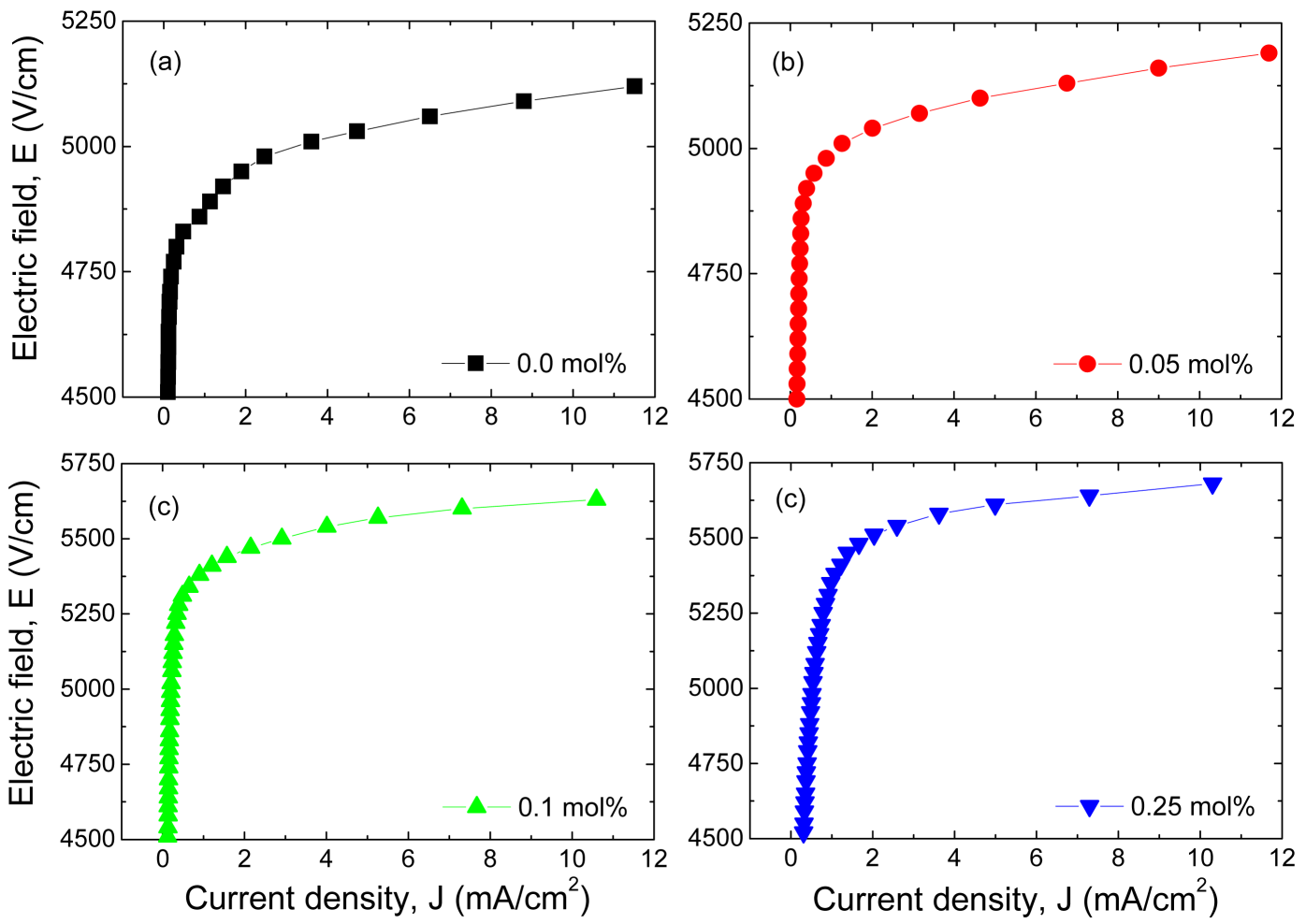

Fig. 4. $J-E$ characteristics of $\mathrm{ZnO}$ ceramics doped with several yttrium contents.

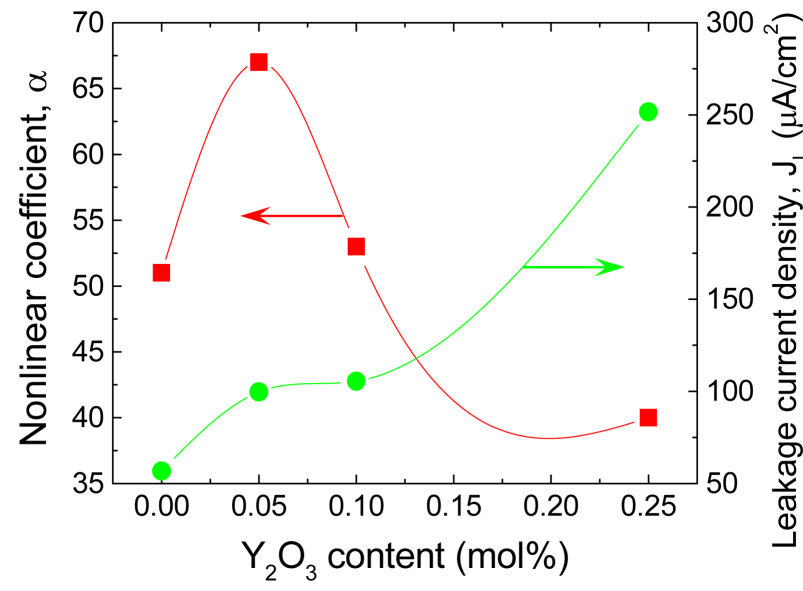

Fig. 5. Nonlinear exponent and leakage current density of $\mathrm{ZnO}$ ceramics as a function of yttrium content.

according to the yttrium content is presented in Fig. 5. As the yttrium content increased, the leakage current density $J_{\mathrm{L}}$ increased from 56.8 to $251.6 \mu \mathrm{A} / \mathrm{cm}^{2}$. A few $J-E$ characteristic parameters with several yttrium contents are listed in Table 1 . These results verify that yttrium doping much more greatly affects $J-E$ characteristics than the microstructure.

Figure 6 presents the modified capacitance-voltage $(C-V)$ characteristic graphs of $\mathrm{ZnO}$ ceramics doped with several yttrium contents. A few $C-V$ characteristic parameters with several yttrium contents are summarized in Table 2 . As the yttrium content increased, the donor concentration $N_{\mathrm{d}}$

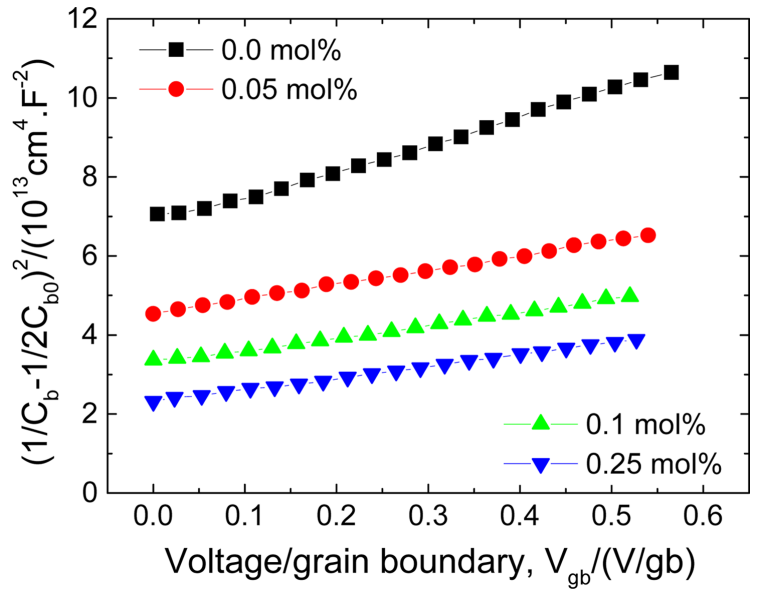

Fig. 6. $C-V$ characteristics of $\mathrm{ZnO}$ ceramics doped with several yttrium contents.

increased from $2.46 \times 10^{17}$ to $5.56 \times 10^{17} \mathrm{~cm}^{-3}$. The yttrium dopant seems to act as a donor, based on the chemical-defect reaction $\mathrm{Y}_{2} \mathrm{O}_{3} \stackrel{\mathrm{ZnO}}{\longrightarrow} 2 \mathrm{Y}_{\mathrm{Zn}}^{\cdot}+2 \mathrm{O}_{\mathrm{O}}+\frac{1}{2} \mathrm{O}_{2}+2 \mathrm{e}^{\prime}$.

As the yttrium content increased, the barrier height $\Phi_{b}$ increased in the range of 1.01-1.24 eV, until the yttrium content reached $0.05 \mathrm{~mol} \%$. However, when the yttrium content was $>0.05 \mathrm{~mol} \%, \Phi_{\mathrm{b}}$ decreased to 0.77 at $0.25 \mathrm{~mol} \%$ yttrium. As the yttrium content increased, the tendency of change in $\Phi_{\mathrm{b}}$ coincided with the tendency of the nonlinear exponent in the $J-E$ characteristics. In general, the higher the value of $\Phi_{b}$, the better the nonlinear properties. Meanwhile, the tendency of change in the interface state density 

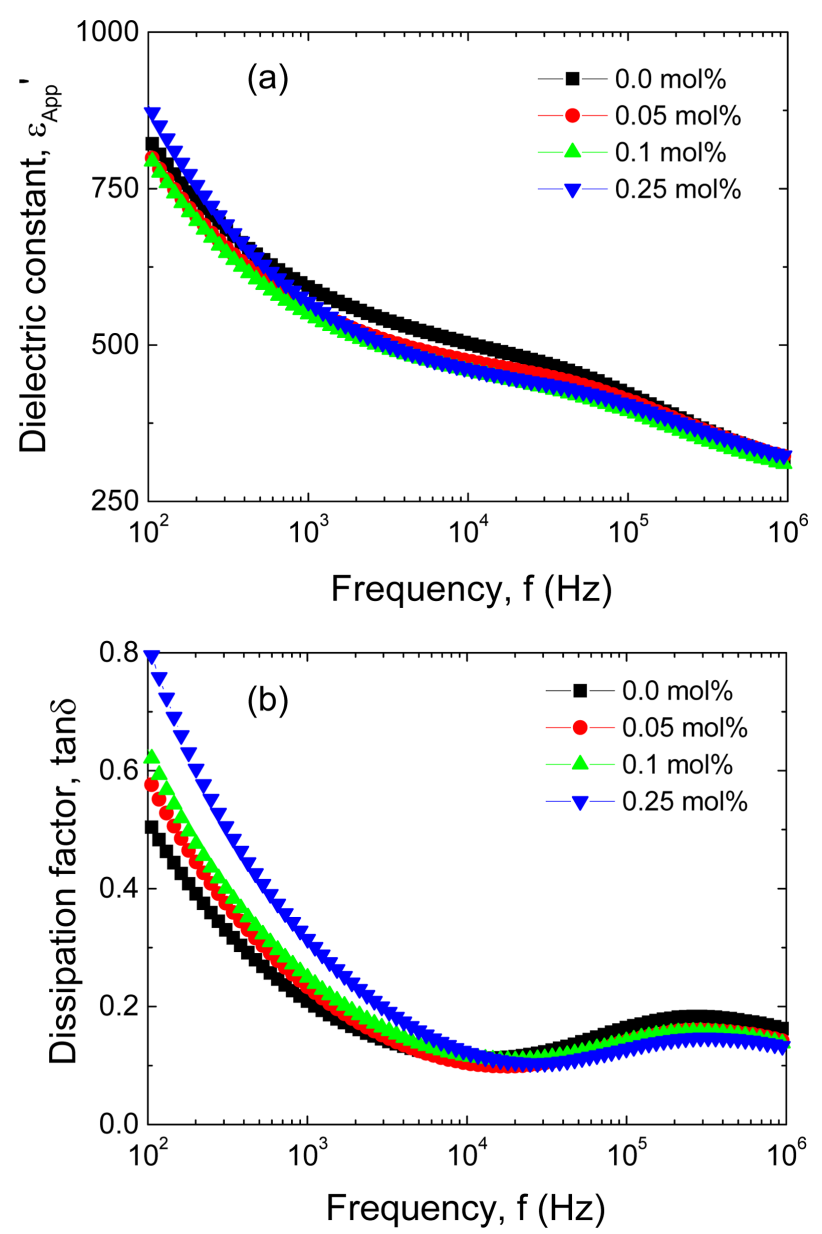

Fig. 7. Dielectric characteristics of $\mathrm{ZnO}$ ceramics doped with several yttrium contents: (a) dielectric constant $\varepsilon_{\mathrm{APP}}$ and (b) dissipation factor tand.

$N_{\mathrm{t}}$ coincided with the tendency of $\Phi_{\mathrm{b}}$ according to the yttrium content. The barrier height is closely connected to the interface state density.

Figure 7 presents the dielectric characteristics of $\mathrm{ZnO}$ ceramics doped with several yttrium contents. Fig. 7(a) shows that the dielectric constant $\varepsilon_{\mathrm{APP}}$ ' decreased with an abrupt drop at $<1 \mathrm{kHz}$ and with a gradual drop at $>100$ $\mathrm{kHz}$ when the frequency increased. On the whole, as shown through the curves, the influence of yttrium doping on the dielectric constant $\varepsilon_{\mathrm{APP}}$ is not significant, when compared with other. ${ }^{21)}$ The behavior of the dielectric constant $\varepsilon_{\mathrm{APP}}$ (at $1 \mathrm{kHz}$ ) according to the yttrium content is presented in Fig. 8. As the yttrium content increased, the dielectric constant

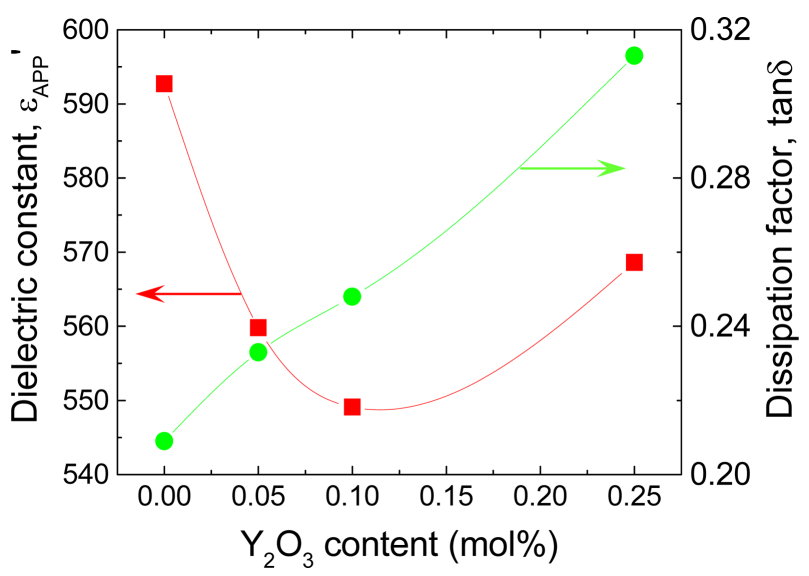

Fig. 8. Dielectric constant and dissipation factor of $\mathrm{ZnO}$ ceramics as a function of yttrium content.

$\varepsilon_{\mathrm{APP}}$ (at $1 \mathrm{kHz}$ ) decreased from 592.7 to 549.1 until the yttrium content reached $0.1 \mathrm{~mol} \%$. When the yttrium content exceeded $0.1 \mathrm{~mol} \%$, the dielectric constant $\varepsilon_{\mathrm{APP}}{ }^{\prime}$ increased up to 568.6 at $0.25 \mathrm{~mol} \%$ yttrium. This trend in the value of the dielectric constant $\varepsilon_{\mathrm{APP}}$ ' is deeply related to the microstructure.

Meanwhile, as shown in Fig. 7(b), the dissipation factor $\tan \delta$ decreased abruptly up to $\sim 20 \mathrm{kHz}$ in all the specimens. All the specimens revealed an absorption peak at $\sim 300 \mathrm{kHz}$, which decreased again when the frequency exceeded $300 \mathrm{kHz}$. The variation in the dissipation factor $\tan \delta$ (at $1 \mathrm{kHz}$ ) according to the yttrium content is presented in Fig. 8. The dissipation factor tan $\delta$ increased in the range of $0.209-0.313$ with increasing yttrium content. This trend in the value of the dissipation factor $\tan \delta$ is closely connected with the leakage current. On the whole, it is assumed that the high dissipation factor $\tan \delta$ in all the specimens is ascribed to a relatively high leakage current. A few dielectric parameters with several yttrium contents are listed in Table 2.

\section{Conclusions}

The varistor properties of zinc-vanadium-based ceramics were comprehensively investigated at $0-0.25 \mathrm{~mol} \%$ yttrium contents. The influence of yttrium doping on the microstructure of varistor ceramics was not as large compared with others with the same doping content: The average grain size was in the narrow range of $5.2-5.5 \mu \mathrm{m}$ and the sintered density was in the narrow range of $5.47-5.51 \mathrm{~g} / \mathrm{cm}^{3}$. However,

Table 2. $C-V$ and Dielectric Characteristic Parameters of $\mathrm{ZnO}$ Ceramics Doped with Several Yttrium Contents

\begin{tabular}{cccccc}
\hline $\begin{array}{c}\text { Yttrium content } \\
(\mathrm{mol})\end{array}$ & $\begin{array}{c}N_{\mathrm{d}} \\
\left(10^{17} \mathrm{~cm}^{-3}\right)\end{array}$ & $\begin{array}{c}\Phi_{\mathrm{b}} \\
(\mathrm{eV})\end{array}$ & $\begin{array}{c}N_{\mathrm{t}} \\
\left(10^{12} \mathrm{~cm}^{-2}\right)\end{array}$ & $\begin{array}{c}\varepsilon_{\text {APP }} \\
(1 \mathrm{kHz})\end{array}$ & $\begin{array}{c}\tan \delta \\
(1 \mathrm{kHz})\end{array}$ \\
\hline 0.0 & 2.46 & 1.01 & 1.53 & 592.7 & 0.209 \\
0.05 & 4.53 & 1.24 & 2.30 & 559.8 & 0.233 \\
0.1 & 5.18 & 1.03 & 2.23 & 549.1 & 0.248 \\
0.25 & 5.56 & 0.77 & 2.01 & 568.6 & 0.313 \\
\hline
\end{tabular}


the nonlinear properties were greatly affected by small changes in yttrium content. The largest effect of yttrium doping on the nonlinear properties was observed when the yttrium content was $0.05 \mathrm{~mol} \%$. The yttrium dopant played the role of a donor, as evident by the increase in electron concentration with increasing yttrium content. It is concluded that zinc-vanadium-based ceramics doped with appropriate yttrium content can be expected to contribute to the development of chip varistors.

\section{REFERENCES}

1. L. M. Levinson and H. R. Philipp, "Zinc Oxide Varistor-a Review," Am. Ceram. Soc. Bull., 65 [4] 639-46 (1986).

2. T. K. Gupta, "Application of Zinc Oxide Varistor," J. Am. Ceram. Soc., 73 [7] 1817-40 (1990).

3. H. R. Pilipp and L. M. Levinson, "The Physics of Metal Oxide Varistors," J. Appl. Phys., 46 [3] 1332-41 (1976).

4. M. Matsuoka, "Nonohmic Properties of Zinc Oxide Ceramics," Jpn. J. Appl. Phys., 10 [6] 736 (1971).

5. K. Mukae, "Zinc Oxide Varistors with Praseodymium Oxide," Am. Ceram. Bull., 66 [10] 1329-31 (1987).

6. C.-W. Nahm and C.-H. Park, "Microstucture, Electrical Properties, and Degradation Behavior of Praseodymium Oxides-based Zinc Oxide Varistors Doped with $\mathrm{Y}_{2} \mathrm{O}_{3}$," J. Mater. Sci., 35 [12] 3037-42 (2000).

7. J.-K. Tsai and T.-B. Wu, "Non-Ohmic Characteristics of ZnO- $\mathrm{V}_{2} \mathrm{O}_{5}$ Ceramics," J. Appl. Phys., 76 [8] 4817-22 (1994).

8. J.-K. Tsai and T.-B. Wu, "Microstructure and Nonohmic Properties of Binary $\mathrm{ZnO}-\mathrm{V}_{2} \mathrm{O}_{5}$ Ceramics Sintered at 900 C," Mater. Lett., 26 [3] 199-203 (1996).

9. H.-H. Hng and P. L. Chan, "Effects of $\mathrm{MnO}_{2}$ Doping in $\mathrm{V}_{2} \mathrm{O}_{5}$-Doped $\mathrm{ZnO}$ Varistor System," Mater. Chem. Phys., 75 [1-3] 61-6 (2002).

10. C.-S. Chen, "Effect of Dopant Valence State of Mn-ions on the Microstructures and Nonlinear Properties of Microwave Sintered $\mathrm{ZnO}-\mathrm{V}_{2} \mathrm{O}_{5}$ Varistors," J. Mater. Sci., 38 [5] 1033-38 (2003).

11. H. Pfeiffer and K. M. Knowles, "Effects of Vanadium and Manganese Concentrations on the Composition, Structure and Electrical Properties of $\mathrm{ZnO}$-rich $\mathrm{MnO}_{2}-\mathrm{V}_{2} \mathrm{O}_{5}-\mathrm{ZnO}$ Varistors," J. Eur. Ceram. Soc., 24 [6] 1199-203 (2004).

12. C.-W. Nahm, "Microstructure and Varistor Properties of
ZnO- $\mathrm{V}_{2} \mathrm{O}_{5}-\mathrm{MnO}_{2}$-Based Ceramic,” J. Mater. Sci., 42 [19] 8370-73 (2007).

13. M. Zhao, X. C. Liu, W. M. Wang, F. Gao, and C. S. Tian, "Two-step Method Fabricating High Nonlinearity ZnVSb Based Varistors," Ceram. Int., 34 [6] 1425-29 (2008).

14. C.-W. Nahm, "Influence of $\mathrm{Nb}$ Addition on Microstructure, Electrical, Dielectric Properties, and Aging Behavior of MnCoDy Modified Zn-V-Based Varistors," J. Mater. Sci.: Mater. Electron., 21 [6] 540-47 (2010).

15. Z. Ming, S. Yu, and T. C. Sheng, "Grain Growth of ZnO$\mathrm{V}_{2} \mathrm{O}_{5}$ Based Varistor Ceramics with Different Antimony Dopants," J. Eur. Ceram. Soc., 31 [13] 2331-37 (2011).

16. M. Mirzayi and M. H. Hekmatshoar, "Effect of $\mathrm{V}_{2} \mathrm{O}_{5}$ on Electrical and Microstructural Properties of $\mathrm{ZnO}$ Ceramics," Phys. B, 414 [4] 50-5 (2013).

17. C.-W. Nahm, Sintering Effect on Pulse Aging Behavior of Zn-V-Mn-Co-Nb Varistors. J. Am. Ceram. Soc., 94 [8] 2269-72 (2011).

18. C.-W. Nahm, "DC Accelerated Aging Behavior of Co-DyNb Doped Zn-V-M-Based Varistors with Sintering Process," J. Mater. Sci.: Mater. Electron., 22 [4] 444-51 (2011).

19. C.-W. Nahm, "Aging Characteristics of $\mathrm{ZnO}-\mathrm{V}_{2} \mathrm{O}_{5}$-based Varistors for Surge Protection Reliability," Microelectron. Reliab., 54 [12] 2836-42 (2014).

20. C.-W. Nahm, "Effect of Sintering Process on Electrical Properties and Ageing Behavior of $\mathrm{ZnO}-\mathrm{V}_{2} \mathrm{O}_{5}-\mathrm{MnO}_{2}-\mathrm{Nb}_{2} \mathrm{O}_{5}$ Varistor Ceramics," J. Mater. Sci.: Mater. Electron., 23 [2] 457-63 (2012).

21. C.-W. Nahm, "Effect of Gadolinia Addition on Varistor Characteristics of Vanadium Oxide-Doped Zinc Oxide Ceramics," J. Mater. Sci.: Mater. Electron., 24 [12] 483946 (2013).

22. J. C. Wurst and J. A. Nelson, "Lineal Intercept Technique for Measuring Grain Size in Two-Phase Polycrystalline Ceramics," J. Am. Ceram. Soc., 55 [97-12] 109-11 (1972).

23. M. Mukae, K. Tsuda, and I. Nagasawa, "Capacitance-vsvoltage Characteristics of ZnO Varistor," J. Appl. Phys., 50 [6] 4475-76 (1979).

24. G. D. Mahan, "Intrinsic Defects in ZnO Varistors," J. Appl. Phys., 54 [7] 3825-32 (1983).

25. T. K. Gupta and W. G. Carlson, "A Grain-boundary Defect Model for Instability/Stability of a $\mathrm{ZnO}$ Varistor," $J$. Mater. Sci., 20 [3] 3487-500 (1985). 